\title{
Gender differences in age-related decline in glomerular filtration rates in healthy people and chronic kidney disease patients
}

\author{
Rong Xu1', Lu-Xia Zhang ${ }^{1}$, Pu-Hong Zhang ${ }^{2}$, Fang Wang ${ }^{1}$, Li Zuo ${ }^{1 *}$, Hai-Yan Wang ${ }^{1}$
}

\begin{abstract}
Background: Since men with chronic kidney disease (CKD) progress faster than women, an accurate assessment of CKD progression rates should be based on gender differences in age-related decline of glomerular filtration rate (GFR) in healthy individuals.

Methods: A Chinese sample population from a stratified, multistage, and clustered CKD screening study was classified into healthy, at-risk, and CKD groups. The gender differences in estimated GFR (eGFR) and age-related eGFR decline were calculated for each group after controlling for blood pressure, fasting glucose levels, serum lipids levels, education level, and smoking status. After referencing to the healthy group, gender-specific multivariate-adjusted rates of decline in eGFR and differences in the rates of decline were calculated for both CKD and at-risk groups.
\end{abstract}

Results: The healthy, at-risk, and CKD groups consisted of 4569, 7434, and 1573 people, respectively. In all the 3 groups, the multivariate-adjusted eGFRs in men were lower than the corresponding eGFRs in women. In addition, in the healthy and at-risk groups, the rates of decline in eGFR in men were lower than the corresponding rates of decline in women (healthy group: $0.51 \mathrm{~mL} \cdot \mathrm{min}^{-1} \cdot 1.73 \mathrm{~m}^{-2} \cdot \mathrm{yr}^{-1} \mathrm{vs} .0 .74 \mathrm{~mL} \cdot \mathrm{min}^{-1} \cdot 1.73 \mathrm{~m}^{-2} \cdot \mathrm{yr}^{-1}$ and at-risk group: $0.60 \mathrm{~mL} \cdot \mathrm{min}^{-1} \cdot 1.73 \mathrm{~m}^{-2} \cdot \mathrm{yr}^{-1}$ vs. $\left.0.73 \mathrm{~mL} \cdot \mathrm{min}^{-1} \cdot 1.73 \mathrm{~m}^{-2} \cdot \mathrm{yr}^{-1}\right)$. However, in the CKD group, the rates of decline in eGFR in men were similar to those in women $\left(0.96 \mathrm{~mL} \cdot \mathrm{min}^{-1} \cdot 1.73 \mathrm{~m}^{-2} \cdot \mathrm{yr}^{-1}\right.$ vs. $\left.0.91 \mathrm{~mL} \cdot \mathrm{min}^{-1} \cdot 1.73 \mathrm{~m}^{-2} \cdot \mathrm{yr}^{-1}\right)$. However, after referencing to the healthy group, the rates of decline in eGFR in men in the at-risk and CKD groups were greater faster than the corresponding rates in women (at-risk group: $0.10 \mathrm{~mL} \cdot \mathrm{min}^{-1} \cdot 1.73 \mathrm{~m}^{-2} \cdot \mathrm{yr}^{-1} \mathrm{vs} .-0.03 \mathrm{~mL} \cdot \mathrm{min}^{-}$ $1 \cdot 1.73 \mathrm{~m}^{-2} \cdot \mathrm{yr}^{-1}$ and CKD group: $0.44 \mathrm{~mL} \cdot \mathrm{min}^{-1} \cdot 1.73 \mathrm{~m}^{-2} \cdot \mathrm{yr}^{-1}$ vs. $0.15 \mathrm{~mL} \cdot \mathrm{min}^{-1} \cdot 1.73 \mathrm{~m}^{-2} \cdot \mathrm{yr}^{-1}$ ).

Conclusion: To accurately assess gender differences in CKD progression rates, gender differences in age-related decline in GFR should be considered.

Keywords: chronic kidney disease, glomerular filtration rate, gender, aging

\section{Background}

Men with chronic kidney disease (CKD) progress to end-stage CKD at a faster rate than women[1,2]. This gender-specific difference cannot be fully explained on the basis of differences in blood pressure, glucose metabolism, or serum cholesterol levels. It is speculated that this difference may be related to gender-specific differences in glomerular structure, hemodynamic condition, activity of local cytokines and hormones, gene

\footnotetext{
*Correspondence: zuolimd@gmail.com

${ }^{1}$ Institute of Nephrology, Peking University First Hospital, Beijing, China

Full list of author information is available at the end of the article
}

expression, and/or the effects of sex hormones on kidney cells $[3,4]$. However, these differences also exist in healthy genders $[5,6]$ and cause gender difference in agerelated loss of glomerular filtration rate (GFR) in healthy population[7-9]. Thus, an accurate assessment of the gender-specific CKD progression rate should be based on the gender differences in age-related decline in GFR in healthy individuals. In addition, some previous studies did not observe a faster progression of CKD in men $[10,11]$. The gender-specific difference in CKD progression rates reflect not only biological differences but also differences in environmental, socioeconomic, lifestyle,
Ciomed Central

() 2010 Xu et al; licensee BioMed Central Ltd. This is an Open Access article distributed under the terms of the Creative Commons Attribution License (http://creativecommons.org/licenses/by/2.0), which permits unrestricted use, distribution, and reproduction in any medium, provided the original work is properly cited. 
and health care factors, which are not usually considered as risk factors for CKD and its progression $[12,13]$. Therefore, to determine the effect of gender alone on CKD progression, these factors should be adjusted. Therefore, we used a randomly sampled population from a well organized CKD screening study to determine gender-specific difference in CKD progression rates after adjusting for the normal age-related GFR decline and after controlling for potential confounding variables, such as health status, socioeconomic status, and lifestyle behaviors.

\section{Methods}

\section{Participants and methods}

We extracted a database of subjects from a stratified CKD cluster sampling study performed in Beijing in 2006[14]. A total of 15,370 adults were selected from 53 primary sampling units and invited to participate. Women needed to be oversampled to obtain sufficient data due to the high male to female sex ratio in China. After weighting, the ratio of men to women in the study was $1: 1.18$. Ultimately, 13,925 subjects completed the survey and physical examination. Overall, the enrollment rate was $90.6 \%$ (92.1\% of females and $89.6 \%$ of males). The ethics committees in Peking university first hospital approved this study. After obtaining informed consent from all subjects, they completed a screening questionnaire to collect information about socioeconomic status (e.g., gender, age, and education), personal and family health history, and lifestyle behaviors (e.g., smoking). Laboratory measurements also were made by welltrained professionals using uniform standards.

Serum creatinine $\left(\mathrm{S}_{\mathrm{cr}}\right)$ was measured by using a kinetic-rate method described by Jaffe. The glomerular filtration rate was estimated by using a modified Modification of Diet in Renal Disease (MDRD) Study formula [15]: estimated GFR (eGFR, $\left.\mathrm{mL} \cdot \mathrm{min}^{-1} \cdot 1.73 \mathrm{~m}^{-2}\right)=175 \times$ standard $\left(\mathrm{S}_{\mathrm{cr}}\right)^{-1.234} \times$ age $^{-0.179} \times 0.79$ (if female).

Urine albumin and creatinine measurements were made from morning spot urine samples. Urine albumin was measured by using an immunoturbidimetric assay (Audit Diagnostics, Cork, Ireland) and urine creatinine was measured by using Jaffe's kinetic method on a Hitachi 7170 chemistry analyzer (Tokyo, Japan). Albuminuria was diagnosed if the urine albumin/creatinine ratio was $\geq 17 \mathrm{mg} \cdot \mathrm{g}^{-1}$ for men or $\geq 25 \mathrm{mg} \cdot \mathrm{g}^{-1}$ for women [16] and proteinuria was diagnosed if this ratio was $\geq 300 \mathrm{mg} \cdot \mathrm{g}^{-1}$ for either men or women.

Hypertension was defined as measurement of systolic blood pressure $\geq 140 \mathrm{mmHg}$ or diastolic blood pressure $\geq 90 \mathrm{mmHg}$, having been diagnosed with hypertension at least twice, or taking an antihypertensive medication at the time of the survey.
Diabetes was defined as measurement of a fasting glucose level $>6.9 \mathrm{mmol} \cdot \mathrm{L}^{-1}$, a previous diagnosis of diabetes, or taking insulin or anti-diabetic medication at the time of the survey.

Dyslipidemia was defined as measurement of total cholesterol $(\mathrm{TC}) \geq 6.22 \mathrm{mmol} \cdot \mathrm{L}^{-1}$, triglyceride (TG) $\geq 2.26 \mathrm{mmol} \cdot \mathrm{L}^{-1}$, high-density lipoprotein (HDL) $<1.04 \mathrm{mmol} \cdot \mathrm{L}^{-1}$, or low-density lipoprotein (LDL) $\geq 4.14 \mathrm{mmol} \cdot \mathrm{L}^{-1}$; a previous diagnosis of dyslipidemia; or taking lipid-lowering medication at the time of the survey.

Obesity was defined as having a body mass index $(\mathrm{BMI}) \geq 28 \mathrm{~kg} \cdot \mathrm{m}^{-2}\left(\mathrm{BMI}=\right.$ weight $/\left(\right.$ height $\left.\left.^{2}\right)\right)$.

Individuals whose eGFR was $>200 \mathrm{~mL} \cdot \mathrm{min}^{-1} \cdot 1.73 \mathrm{~m}^{-2}$ $(\mathrm{n}=33)$ or $<15 \mathrm{~mL} \cdot \mathrm{min}^{-1} \cdot 1.73 \mathrm{~m}^{-2}(\mathrm{n}=57)$ were excluded from this study. Participants were divided into 3 groups according to their health status: those with albuminuria or eGFR $<60 \mathrm{~mL} \cdot \mathrm{min}^{-1} \cdot 1.73 \mathrm{~m}^{-2}$ were placed in the CKD group; those without CKD but with hypertension, diabetes, dyslipidemia, or obesity were placed in the at-risk group; those without CKD or other medical conditions were placed in the healthy group. We also used proteinuria as a definition of CKD and performed a separate statistical analysis as described below because currently there is no consensus about defining CKD by microalbuminuria or macroalbuminuria. Some authors only consider microalbuminuria to be a risk factor for CKD such as (pre)hypertension or diabetes and its reproducibility of microalbuminuria tests is limited [34].

\section{Statistical analyses}

General characteristics in each health status group

Sociodemographic characteristics (age, highest education level), health indicators (BMI, fasting glucose level, serum lipid levels, eGFR), and lifestyle behaviors (smoking) of each gender were described by descriptive statistics. The differences in these variables among genders were examined by using chi-square statistics for categorical variables and Student's t-test for continuous values. Gender-specific adjusted eGFRs in each health status group For each health status group, a linear model was constructed with eGFR as the dependent variable, gender as the independent variable, and confounding factors (systolic blood pressure, diastolic blood pressure, BMI, fasting glucose level, serum lipid levels, highest education level, and smoking) as covariates. This model was used to calculate the least squares means of eGFR (adjusted eGFR) and to compare eGFRs between genders within each health status group.

\section{Gender-specific rates of decline of eGFR in each health}

\section{status group}

A linear model was constructed for each health status group. In these models, the dependent variable was 
eGFR and the independent variables were age, gender, and interaction of age and gender. These models were used to calculate the gender-specific rates of decline of eGFR and to test gender-specific differences. Subsequently, confounding factors were added to these models as covariates to calculate the adjusted gender-specific rates of decline of eGFR.

\section{Adjusted gender-specific rates of decline of eGFR (referenced to healthy group) in CKD and at-risk groups}

A linear regression model was constructed for each gender. In these models, the variables were (1) eGFR (dependent variable); (2) age, health status, and interaction of age and health status (independent variables); and (3) the aforementioned confounding factors (covariates). This model was used to calculate the adjusted gender-specific rates of decline of eGFR (referenced to the healthy group) for the CKD and at-risk groups. In addition, a linear regression model was constructed with the following variables: (1) eGFR (dependent variable); (2) age, health status, gender, and interactions of age and health status, age and gender, health status and gender, age and health status and gender (independent variables); and (3) the aforementioned confounding factors (covariates). This model was used to test for statistically significant differences between men and women for the adjusted gender-specific rates of decline of eGFR (referenced to the healthy group) for the CKD and at-risk groups.

All statistical analyses were performed using Statistical Analysis System software, version 9.0 (SAS Institute Inc., Cary, NC, USA). Tests for association were considered to be statistically significant when the p-values were less than 0.05 .

\section{Results}

The healthy, at-risk, and CKD groups consisted of 4569, 7434, and 1573 people, respectively. There were 1396 individuals (10.04\%) with microalbuminuria, 104 (0.75\%) with proteinuria, and $261(1.88 \%)$ with eGFR $<60$ $\mathrm{mL} \cdot \mathrm{min}^{-1} \cdot 1.73 \mathrm{~m}^{-2}$. In the healthy group, men had higher BMIs, blood pressures, fasting glucose levels, serum lipid levels, and lower education levels than women of similar ages. In the at-risk group, men were younger, had higher diastolic blood pressures, TG levels, and education levels but lower levels of LDL, TC, and HDL than women. In the CKD group, men had higher blood pressures, TG levels, and education levels but lower HDL levels than women. In each health status group, men were more likely to be smokers. Compared to individuals in the healthy group, those in the at-risk and CKD groups were older and fatter and had higher blood pressures and serum lipid levels. For men, the prevalence of smoking was similar in all health status groups and the CKD group had significantly lower education levels than the healthy or at-risk groups. For women, the at-risk and CKD groups had significantly lower education levels and more smokers than the healthy group (Table 1).

The gender differences of adjusted eGFRs in each health status and age groups are shown in Table 2 . In the healthy group, men younger than 60 years old had significantly lower eGFRs than women of similar ages. After age 60, this relationship reversed but the difference was not significant. In the at-risk group, men younger than 70 years old had significantly lower eGFRs than women of similar ages. However, in the CKD group, both men and women had similar eGFRs in each age group.

As shown in Table 3, the unadjusted rates of decline of eGFR were $0.51 \mathrm{~mL} \cdot \mathrm{min}^{-1} \cdot 1.73 \mathrm{~m}^{-2} \cdot \mathrm{yr}^{-1}$ for men and $0.75 \mathrm{~mL} \cdot \mathrm{min}^{-1} \cdot 1.73 \mathrm{~m}^{-2} \cdot \mathrm{yr}^{-1}$ for women in the healthy group ( $\mathrm{p}<0.05$ ), $0.53 \mathrm{~mL} \cdot \mathrm{min}^{-1} \cdot 1.73 \mathrm{~m}^{-2} \cdot \mathrm{yr}^{-1}$ for men and $0.67 \mathrm{~mL} \cdot \mathrm{min}^{-1} \cdot 1.73 \mathrm{~m}^{-2} \cdot \mathrm{yr}^{-1}$ for women in the at-risk group ( $\mathrm{p}<0.05$ ), and $0.89 \mathrm{~mL} \cdot \mathrm{min}^{-1} \cdot 1.73 \mathrm{~m}^{-2} \cdot \mathrm{yr}^{-1}$ for men and $0.88 \mathrm{~mL} \cdot \mathrm{min}^{-1} \cdot 1.73 \mathrm{~m}^{-2} \cdot \mathrm{yr}^{-1}$ for women in the CKD group ( $p>0.05)$. After adjusting for covariates, the rates of decline of eGFR were $0.51 \mathrm{~mL} \cdot \mathrm{min}^{-1} \cdot 1.73 \mathrm{~m}^{-2} \cdot \mathrm{yr}^{-1}$ for men and $0.74 \mathrm{~mL} \cdot \mathrm{min}^{-1} \cdot 1.73 \mathrm{~m}^{-2} \cdot \mathrm{yr}^{-1}$ for women in the healthy group $(\mathrm{p}<0.05), 0.60 \mathrm{~mL} \cdot \mathrm{min}^{-1} \cdot 1.73 \mathrm{~m}^{-2} \cdot \mathrm{yr}^{-1}$ for men and $0.73 \mathrm{~mL} \cdot \mathrm{min}^{-1} \cdot 1.73 \mathrm{~m}^{-2} \cdot \mathrm{yr}^{-1}$ for women in the at-risk group $(\mathrm{p}<0.05)$, and $0.96 \mathrm{~mL} \cdot \mathrm{min}^{-1} \cdot 1.73 \mathrm{~m}^{-2} \cdot \mathrm{yr}^{-1}$ for men and $0.91 \mathrm{~mL} \cdot \mathrm{min}^{-1} \cdot 1.73 \mathrm{~m}^{-2} \cdot \mathrm{yr}^{-1}$ for women in the CKD group ( $\mathrm{p}>0.05$ ). In addition, we calculated the variation in the rates of decline of eGFR before and after the age of 50 . However, there was no significant difference for either gender in each health status group.

Table 3 also shows that the adjusted rates of decline of eGFR (referenced to the healthy group) was $0.10 \mathrm{~mL} \cdot \mathrm{min}^{-1} \cdot 1.73 \mathrm{~m}^{-2} \cdot \mathrm{yr}^{-1}(\mathrm{p}<0.05)$ for men and $-0.03 \mathrm{~mL} \cdot \mathrm{min}^{-1} \cdot 1.73 \mathrm{~m}^{-2} \cdot \mathrm{yr}^{-1}(\mathrm{p}>0.05)$ for women in the at-risk group and $0.44 \mathrm{~mL} \cdot \mathrm{min}^{-1} \cdot 1.73 \mathrm{~m}^{-2} \cdot \mathrm{yr}^{-1}$ $(\mathrm{p}<0.05)$ for men and $0.15 \mathrm{~mL} \cdot \mathrm{min}^{-1} \cdot 1.73 \mathrm{~m}^{-2} \cdot \mathrm{yr}^{-1}$ $(p<0.05)$ for women in the CKD group. The gender difference of the adjusted rate of decline of eGFR (referenced to the healthy group) was statistically significant for the CKD group $\left(0.29 \mathrm{~mL} \cdot \mathrm{min}^{-1} \cdot 1.73 \mathrm{~m}^{-2} \cdot \mathrm{yr}^{-1}, \mathrm{p}<0.05\right)$ but not the at-risk group $\left(0.10 \mathrm{~mL} \cdot \mathrm{min}^{-1} \cdot 1.73 \mathrm{~m}^{-2} \cdot \mathrm{yr}^{-1}\right.$, $\mathrm{p}>0.05)$.

When we used proteinuria to define CKD, we obtained different results for the CKD group (Table 4). For men, the difference of the adjusted rate of decline of eGFR between the CKD and healthy groups increased from $0.44 \mathrm{~mL} \cdot \mathrm{min}^{-1} \cdot 1.73 \mathrm{~m}^{-2} \cdot \mathrm{yr}^{-1}(\mathrm{p}<0.05)$ (Table 3) to $0.51 \mathrm{~mL} \cdot \mathrm{min}^{-1} \cdot 1.73 \mathrm{~m}^{-2} \cdot \mathrm{yr}^{-1}(\mathrm{p}<0.05)$ (Table 4). For women, this difference increased from $0.15 \mathrm{~mL} \cdot \mathrm{min}^{-}$ ${ }^{1} \cdot 1.73 \mathrm{~m}^{-2} \cdot \mathrm{yr}^{-1}(\mathrm{p}<0.05)$ (Table 3$)$ to $0.20 \mathrm{~mL} \cdot \mathrm{min}^{-1} \cdot 1.73$ $\mathrm{m}^{-2} \cdot \mathrm{yr}^{-1}(\mathrm{p}<0.05)$ (Table 4). However, the gender difference of the adjusted rate of decline of eGFR in the CKD 
Table 1 Characteristics of study participants in healthy, at-risk, and CKD groups

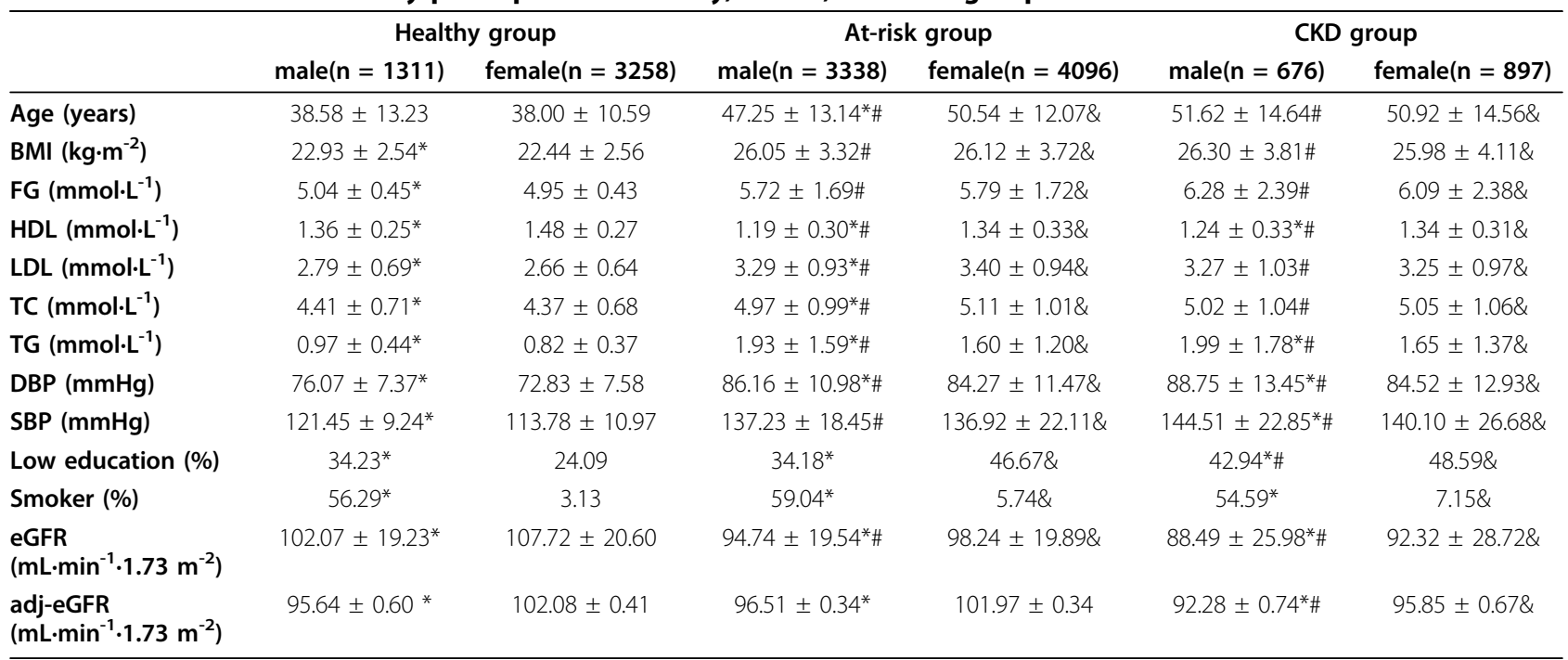

BMI: body mass index; FG: fasting glucose; HDL: high-density lipoprotein; LDL: low-density lipoprotein; TC: total cholesterol; TG: triglyceride; DBP: diastolic blood pressure; SBP: systolic blood pressure; eGFR: estimated glomerular filtration rate; adj-eGFR: eGFR adjusted for age, blood pressure, fasting glucose level, serum lipid level, education level, and smoking

*: Compared to women in the same health status group, $p<0.05$

\#: Compared to men in the healthy group, $p<0.05$

\&: Compared to women in the healthy group, $p<0.05$

group did not show any significant change $(0.29$ $\mathrm{mL} \cdot \mathrm{min}^{-1} \cdot 1.73 \mathrm{~m}^{-2} \cdot \mathrm{yr}^{-1}$ vs. $\left.0.31 \mathrm{~mL} \cdot \mathrm{min}^{-1} \cdot 1.73 \mathrm{~m}^{-2} \cdot \mathrm{yr}^{-1}\right)$. Moreover, these changes were quantitative but not qualitative, which was partly due to the significantly smaller sample size in the CKD group when proteinuria was used to define CKD.

\section{Discussion}

Currently information about gender differences in GFRs in healthy individuals is limited and conflicting. For example, our observation that men younger than 60 years old had lower eGFRs than women of similar ages is both consistent[17] and inconsistent[7,18-21] with previous studies. In addition, the information about gender differences in age-related rates of decline of GFR is not very consistent. For instance, our observation that healthy men had lower rates of decline of eGFR than healthy women is in agreement with some previous studies $[8,22]$ but not others $[7,21,23]$. Unlike the participants in previous studies, who were voluntary kidney donors $[7,8,18,20,21,23]$ or local residents[17,19], participants in this study were selected from a prior stratified cluster sampling study, which represented the study population well and minimized selection bias.

Some earlier studies showed an increase in the rates of decline of GFR in healthy individuals older than 40 or 50 years old $[18,19,21]$ or a constant GFR for women younger than 50 years old[23]. However, other studies observed a linear relationship between GFR and age $[8,20]$. In this study, we did not find any significant difference in the rate of decline of eGFR before or after the age of 50 for either gender. In addition, although we observed that older healthy subjects had significantly lower eGFRs than young healthy subjects, the difference was not as large as we expected. This finding is consistent with the hypothesis that kidney function may not decrease with age but rather with age-related increases in the incidence of degenerative diseases and risk factors for vascular and kidney disease. In most former studies, few study participants were elderly and exclusion criteria were more relaxed than in our study. Any study about the rate of decline of GFR in healthy individuals that does not exclude all possible confounding factors that can affect the GFR, which are common in the elderly, would be expected to show an increased rate of decline of GFR in the elderly.

Our observation that the rate of decline of eGFR in men was slower in the healthy group but faster in the CKD group could be explained by epidemiology studies. In general, men have a higher incidence and prevalence of end-stage renal disease (ESRD) than women [24,25]; however, most population-based CKD screening studies show that men have a similar[14,26] or lower[27-29] prevalence of CKD than women. This discrepancy suggests 2 potential mechanisms for the rate of decline of GFR between non-CKD and CKD stages. One possible explanation is that renal function is preserved as healthy individuals age at the expense of a gradual decrease in the renal functional reserve[30]. Men may have a higher renal functional reserve to compensate for the 
Table 2 Gender differences of adjusted eGFR $^{\dagger}\left(\mathrm{mL} \cdot \mathrm{min}^{-1} \cdot 1.73 \mathrm{~m}^{-2}\right.$, mean \pm standard error) in each age group in healthy, at-risk, and CKD groups

\begin{tabular}{|c|c|c|c|c|c|c|c|}
\hline \multirow[t]{2}{*}{ Age group } & & \multicolumn{2}{|l|}{ Healthy group } & \multicolumn{2}{|l|}{ At-risk group } & \multicolumn{2}{|l|}{ CKD group } \\
\hline & & Men & Women & Men & Women & Men & Women \\
\hline \multirow[t]{4}{*}{$18-30$ years } & Creatinine & $83.94 \pm 0.59^{*}$ & $64.41 \pm 0.32$ & $84.70 \pm 0.66^{*}$ & $64.55 \pm 0.70$ & $86.72 \pm 7.17^{*}$ & $66.61 \pm 1.69$ \\
\hline & eGFR & $109.13 \pm 1.03^{*}$ & $118.89 \pm 0.76$ & $107.63 \pm 1.27^{*}$ & $117.87 \pm 1.63$ & $111.38 \pm 4.70$ & $116.48 \pm 3.30$ \\
\hline & adj-eGFR & $107.83 \pm 1.07^{*}$ & $119.56 \pm 0.75$ & $107.59 \pm 1.22^{*}$ & $117.94 \pm 1.81$ & $108.39 \pm 4.13$ & $118.52 \pm 3.34$ \\
\hline & $\mathbf{N}$ & 384 & 729 & 328 & 162 & 47 & 69 \\
\hline \multirow[t]{4}{*}{$30-40$ years } & Creatinine & $81.79 \pm 0.63^{*}$ & $65.47 \pm 0.28$ & $84.76 \pm 0.51^{*}$ & $66.29 \pm 0.41$ & $87.96 \pm 1.57^{*}$ & $68.45 \pm 1.41$ \\
\hline & eGFR & $105.13 \pm 1.04^{*}$ & $109.00 \pm 0.57$ & $100.89 \pm 0.97^{*}$ & $107.14 \pm 0.86$ & $104.27 \pm 2.41$ & $106.62 \pm 2.35$ \\
\hline & adj-eGFR & $104.50 \pm 1.08^{*}$ & $109.22 \pm 0.58$ & $101.42 \pm 0.93^{*}$ & $106.62 \pm 0.97$ & $106.25 \pm 2.73$ & $105.11 \pm 2.27$ \\
\hline & $\mathbf{N}$ & 344 & 1077 & 556 & 514 & 90 & 126 \\
\hline \multirow[t]{4}{*}{$40-50$ years } & Creatinine & $82.84 \pm 0.61^{*}$ & $65.89 \pm 0.30$ & $84.82 \pm 0.35^{*}$ & $66.45 \pm 0.27$ & $88.83 \pm 1.97^{*}$ & $72.87 \pm 1.50$ \\
\hline & eGFR & $98.48 \pm 0.94^{*}$ & $103.93 \pm 0.61$ & $95.82 \pm 0.54^{*}$ & $102.65 \pm 0.54$ & $93.69 \pm 1.64$ & $96.38 \pm 1.57$ \\
\hline & adj-eGFR & $98.66 \pm 1.09^{*}$ & $103.88 \pm 0.58$ & $96.13 \pm 0.58^{*}$ & $102.42 \pm 0.52$ & $94.85 \pm 1.83$ & $95.56 \pm 1.52$ \\
\hline & $\mathbf{N}$ & 310 & 1026 & 1053 & 1308 & 175 & 248 \\
\hline \multirow[t]{4}{*}{$50-60$ years } & Creatinine & $84.13 \pm 0.79^{*}$ & $68.20 \pm 0.51$ & $86.19 \pm 0.39^{*}$ & $68.85 \pm 0.28$ & $92.02 \pm 1.91^{*}$ & $76.72 \pm 2.06$ \\
\hline & eGFR & $93.47 \pm 1.15^{*}$ & $96.31 \pm 0.95$ & $90.91 \pm 0.57^{*}$ & $94.94 \pm 0.49$ & $87.49 \pm 1.74$ & $90.32 \pm 1.86$ \\
\hline & adj-eGFR & $93.26 \pm 1.29^{*}$ & $96.42 \pm 0.92$ & $90.89 \pm 0.60^{*}$ & $94.95 \pm 0.49$ & $88.21 \pm 1.92$ & $89.71 \pm 0.75$ \\
\hline & $\mathbf{N}$ & 184 & 340 & 845 & 1212 & 170 & 204 \\
\hline \multirow[t]{4}{*}{$60-70$ years } & Creatinine & $83.57 \pm 1.37^{*}$ & $70.74 \pm 1.28$ & $87.53 \pm 0.61^{*}$ & $70.14 \pm 0.41$ & $101.27 \pm 3.22^{*}$ & $85.45 \pm 4.76$ \\
\hline & eGFR & $91.14 \pm 1.87$ & $88.76 \pm 2.08$ & $86.13 \pm 0.78^{*}$ & $89.83 \pm 0.70$ & $76.30 \pm 2.26$ & $80.74 \pm 2.45$ \\
\hline & adj-eGFR & $91.20 \pm 2.02$ & $88.70 \pm 2.08$ & $86.03 \pm 0.88^{*}$ & $89.76 \pm 0.67$ & $75.54 \pm 2.43$ & $81.63 \pm 2.19$ \\
\hline & $\mathbf{N}$ & 62 & 59 & 351 & 580 & 100 & 125 \\
\hline \multirow[t]{4}{*}{ 70-years } & Creatinine & $84.92 \pm 2.42^{*}$ & $72.16 \pm 1.77$ & $88.77 \pm 0.79^{*}$ & $72.72 \pm 0.55$ & $109.46 \pm 2.99^{*}$ & $86.89 \pm 1.95$ \\
\hline & eGFR & $87.46 \pm 3.11$ & $84.33 \pm 2.66$ & $82.48 \pm 0.95$ & $83.75 \pm 0.85$ & $67.07 \pm 1.94$ & $71.39 \pm 2.14$ \\
\hline & adj-eGFR & $90.17 \pm 3.10$ & $81.62 \pm 3.10$ & $82.69 \pm 1.06$ & $83.50 \pm 0.84$ & $65.82 \pm 2.30$ & $71.83 \pm 1.97$ \\
\hline & $\mathbf{N}$ & 27 & 27 & 205 & 320 & 94 & 125 \\
\hline
\end{tabular}

${ }^{\dagger}$ : Controlled for age, blood pressure, fasting glucose level, serum lipid level, education level, and smoking frequency

*: Compared to women in the same health status group, $\mathrm{p}<0.05$

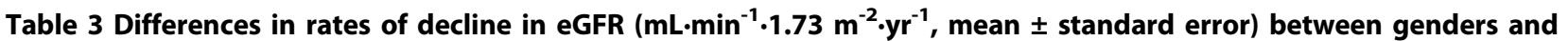
between groups

\begin{tabular}{|c|c|c|c|c|c|c|}
\hline & \multicolumn{2}{|c|}{ Health group $(n=4569)$} & \multicolumn{2}{|c|}{ Risk group $(n=7434)$} & \multicolumn{2}{|c|}{ CKD group $(n=1573)$} \\
\hline & $\begin{array}{c}\text { Male } \\
(\mathrm{n}=1311)\end{array}$ & $\begin{array}{c}\text { Female } \\
(\mathrm{n}=3258)\end{array}$ & $\begin{array}{c}\text { Male } \\
(\mathrm{n}=3338)\end{array}$ & $\begin{array}{c}\text { Female } \\
(n=4096)\end{array}$ & $\begin{array}{c}\text { Male } \\
(n=676)\end{array}$ & $\begin{array}{l}\text { Female } \\
(\mathrm{n}=897)\end{array}$ \\
\hline Unadjusted rates of decline in eGFR & $0.51 \pm 0.04^{*}$ & $0.75 \pm 0.03$ & $0.53 \pm 0.02^{*}$ & $0.67 \pm 0.02$ & $0.89 \pm 0.06$ & $0.88 \pm 0.06$ \\
\hline Covariate-adjusted rates of decline in $\mathrm{eGFR}^{\dagger}$ & $0.52 \pm 0.04^{*}$ & $0.75 \pm 0.04$ & $0.62 \pm 0.03^{*}$ & $0.71 \pm 0.03$ & $0.94 \pm 0.06$ & $0.90 \pm 0.08$ \\
\hline $\begin{array}{l}\text { Covariate-adjusted rates of decline in eGFR } \\
\text { (referenced to healthy group) }\end{array}$ & - & - & $0.10 \pm 0.05 \&$ & $-0.03 \pm 0.04$ & $0.44 \pm 0.06 \&$ & $0.15 \pm 0.06 \&$ \\
\hline $\begin{array}{l}\text { Gender difference in covariate-adjusted rates } \\
\text { of decline in } \text { GFFR }^{\dagger} \text { (referenced to healthy } \\
\text { group) }\end{array}$ & \multicolumn{2}{|c|}{-} & \multicolumn{2}{|c|}{$0.10 \pm 0.06$} & \multicolumn{2}{|c|}{$0.29 \pm 0.09 \#$} \\
\hline
\end{tabular}

*: Compared to women in the same health status group, $p<0.05$

\&: Compared to healthy group in the same gender, $\mathrm{p}<0.05$

$\#: p<0.05$

${ }^{\dagger}$ : Controlled for age, blood pressure, fasting glucose level, serum lipid level, education level, and smoking frequency 
Table 4 Differences in rates of decline in eGFR $\left(\mathrm{mL} \cdot \mathrm{min}^{-1} \cdot 1.73 \mathrm{~m}^{-2} \cdot \mathrm{yr}^{-1}\right.$, mean \pm standard error) within genders and between groups when proteinuria was used to define CKD

\begin{tabular}{|c|c|c|c|c|c|c|}
\hline & \multicolumn{2}{|c|}{ Health group $(n=4660)$} & \multicolumn{2}{|c|}{ Risk group $(n=8566)$} & \multicolumn{2}{|c|}{ CKD group $(n=341)$} \\
\hline & $\begin{array}{c}\text { Male } \\
(n=1353)\end{array}$ & $\begin{array}{c}\text { Female } \\
(n=3307)\end{array}$ & $\begin{array}{c}\text { Male } \\
(\mathrm{n}=3836)\end{array}$ & $\begin{array}{c}\text { Female } \\
(n=4730)\end{array}$ & $\begin{array}{c}\text { Male } \\
(n=130)\end{array}$ & $\begin{array}{l}\text { Female } \\
(n=211)\end{array}$ \\
\hline Unadjusted rates of decline in eGFR & $0.52 \pm 0.04^{*}$ & $0.75 \pm 0.03$ & $0.52 \pm 0.02^{*}$ & $0.67 \pm 0.02$ & $0.97 \pm 0.08$ & $0.91 \pm 0.07$ \\
\hline Covariate-adjusted rates of decline in eGFR ${ }^{\dagger}$ & $0.52 \pm 0.04^{*}$ & $0.74 \pm 0.04$ & $0.61 \pm 0.03^{*}$ & $0.71 \pm 0.03$ & $1.03 \pm 0.08$ & $0.97 \pm 0.10$ \\
\hline $\begin{array}{l}\text { Covariate-adjusted rates of decline in eGFR } \\
\text { (referenced to healthy group) }\end{array}$ & - & - & $0.10 \pm 0.04 \&$ & $-0.03 \pm 0.04$ & $0.51 \pm 0.08 \&$ & $0.20 \pm 0.07 \&$ \\
\hline $\begin{array}{l}\text { Gender difference of covariate adjusted rates } \\
\text { of decline in } \text { eGFR }^{\dagger} \text { (referenced to healthy } \\
\text { group) }\end{array}$ & \multicolumn{2}{|c|}{-} & \multicolumn{2}{|c|}{$0.09 \pm 0.06$} & \multicolumn{2}{|c|}{$0.31 \pm 0.10 \#$} \\
\hline
\end{tabular}

accumulation of sclerotic glomeruli during aging. Indeed, previous studies show that healthy men have a greater ability to maintain their GFRs by increasing the filtration fraction than women[31]. In addition, genderspecific differences in glomerular hemodynamic may contribute to differences in age-related decline of GFRs. Another possible explanation is that although the whole-body levels[6] and renal levels[32] of nitric oxide, a vasodilator, are higher in healthy premenstrual women than healthy men, which may cause a higher GFR in premenstrual women, the renal vasculature of men may become increasingly dependent on nitric oxide with age compared with that of women[5]. If this is true, then any renal disease that interferes with nitric oxide production may cause kidney damage to progress more quickly in men than in women.

This study had 3 potential limitations. First, the use of estimated GFR to assess renal function in healthy individuals could be prone to measurement bias[17]. However, when we used the Cockcroft-Gault formula, which was developed from healthy individuals and is more accurate than the MDRD formula[17], to assess renal function in healthy individuals, men still had lower eGFRs and slower age-related rates of decline of eGFR than women. Furthermore, when we excluded individuals younger than 30 years old (who are healthier), our results were similar. Second, we had to estimate GFRs rather than measure them directly and only a single measurement of serum creatinine was available for each participant. In addition, morning spot urine samples were collected rather than first morning void urine samples. It is known that first morning void urine samples may provide more accurate results of albuminuria [33] and that the reproducibility of microalbuminuria tests is limited (60-70\%) [34]. Despite these limitations, the procedures used in this study were chosen due to the expense and inherent difficulties of directly measuring GFRs and collecting first-morning void urine samples and many blood and urine samples in a study with more than 10,000 participants. Third, estimating agerelated rates of decline of eGFR from a cross-sectional study undoubtedly produced bias; however, appropriate mathematical models were used to reduce the bias as much as possible. In addition, since men had a higher risk of cardiovascular disease and death with increasing age, especially those with chronic renal insufficiency, the regression line of GFR against age would deviate from its actual trend for a higher non-response rate in men than in women. However, in this study, men had a similar response rate as that in women (89.6\% vs. $92.1 \%)$. Moreover, if a correction were made for the higher nonresponse rate in unhealthy men, who tended to have lower GFRs than participants who responded, then the gender differences in the rate of decline of eGFR would be greater.

\section{Conclusion}

There are gender differences in the decline in GFR and among different health statuses. To accurately evaluate the gender differences in CKD progression rate, the baseline gender differences in age-related decline in GFR in healthy individuals should be considered.

\section{Acknowledgements}

We thank the Institute of Nephrology, Peking University First Hospital and Beijing Centers for Diseases Control and Prevention (CDC) \& Centers for Preventive Medical Research for providing the data reported in this study.

\section{Author details}

${ }^{1}$ Institute of Nephrology, Peking University First Hospital, Beijing, China. ${ }^{2}$ Beijing Centers for Diseases Control and Prevention (CDC) \& Centers for Preventive Medical Research, Beijing, China.

\section{Authors' contributions}

RX analyzed data and wrote the paper $\mathrm{LXZ}, \mathrm{PHZ}$, and FW performed research.

$\mathrm{LZ}$ and HYW designed research.

All authors read and approved the final manuscript.

\section{Competing interests}

The authors declare that they have no competing interests.

Received: 20 March 2010 Accepted: 23 August 2010

Published: 23 August 2010

\section{References}

1. Neugarten J, Acharya A, Silbiger SR: Effect of gender on the progression of nondiabetic renal disease: a meta-analysis. J Am Soc Nephrol 2000, 11:319-29. 
2. Silbiger SR, Neugarten J: The impact of gender on the progression of chronic renal disease. Am J Kidney Dis 1995, 25:515-33.

3. Silbiger SR, Neugarten J: The role of gender in the progression of renal disease. Adv Ren Replace Ther 2003, 10:3-14.

4. Lu H, Klaassen C: Gender differences in mRNA expression of ATP-binding cassette efflux and bile acid transporters in kidney, liver, and intestine of 5/6 nephrectomized rats. Drug Metab Dispos 2008, 36:16-23.

5. Sofia BAhmed, Naomi DLFisher, Norman K: Hollenberg. Gender and the Renal Nitric Oxide Synthase System in Healthy Humans. Clin J Am Soc Nephrol 2007, 916-931.

6. Forte $P$, Kneale $B J$, Milne $E$, et al: Evidence for a difference in nitric oxide biosynthesis between healthy women and men. Hypertension 1998, 32:730-4.

7. Barai $\mathrm{S}$, Bandopadhayaya $\mathrm{GP}$, Patel $\mathrm{CD}$, et al: Do healthy potential kidney donors in india have an average glomerular filtration rate of $81.4 \mathrm{ml} /$ min? Nephron Physiol 2005, 101:21-6.

8. Rule AD, Gussak HM, Pond GR, et al: Measured and estimated GFR in healthy potential kidney donors. Am J Kidney Dis 2004, 43:112-9.

9. Fliser $D$, Zeier $M$, Nowack $R$, et al: Renal functional reserve in healthy elderly subjects. J Am Soc Nephrol 1993, 3:1371-7.

10. D'Amico G: Influence of clinical and histological features on actuarial renal survival in adult patients with idiopathic IgA nephropathy, membranous nephropathy, and membranoproliferative glomerulonephritis: survey of the recent literature. Am J Kidney Dis 1992, 20:315-23

11. Coggins CH, Breyer Lewis J, Caggiula AW, et al: Differences between women and men with chronic renal disease. Nephrol Dial Transplant 1998, 13:1430-7.

12. Orth SR, Hallan SI: Smoking: a risk factor for progression of chronic kidney disease and for cardiovascular morbidity and mortality in renal patients-absence of evidence or evidence of absence? Clin J Am Soc Nephrol 2008, 3:226-36.

13. Taal MW, Brenner BM: Predicting initiation and progression of chronic kidney disease: Developing renal risk scores. Kidney Int 2006, 70:1694-705.

14. Zhang L, Zhang P, Wang F, et al: Prevalence and factors associated with CKD: a population study from Beijing. Am J Kidney Dis 2008, 51:373-84.

15. Ma YC, Zuo L, Chen JH, et al: Modified glomerular filtration rate estimating equation for Chinese patients with chronic kidney disease. $J$ Am Soc Nephrol 2006, 17:2937-44.

16. Mattix HJ, Hsu CY, Shaykevich S, et al: Use of the albumin/creatinine ratio to detect microalbuminuria: implications of sex and race. J Am Soc Nephrol 2002, 13:1034-9.

17. Vervoort G, Willems HL, Wetzels JF: Assessment of glomerular filtration rate in healthy subjects and normoalbuminuric diabetic patients: validity of a new (MDRD) prediction equation. Nephrol Dial Transplant 2002, 17:1909-13.

18. Grewal GS, Blake GM: Reference data for 51Cr-EDTA measurements of the glomerular filtration rate derived from live kidney donors. Nucl Med Commun 2005, 26:61-5.

19. Klingensmith WC, Briggs DE, Smith WI: Technetium-99 m-MAG3 renal studies: normal range and reproducibility of physiologic parameters as a function of age and sex. J Nucl Med 1994, 35:1612-7.

20. Slack TK, Wilson DM: Normal renal function: CIN and CPAH in healthy donors before and after nephrectomy. Mayo Clin Proc 1976, 51:296-300.

21. Granerus G, Aurell M: Reference values for $51 \mathrm{Cr}$-EDTA clearance as a measure of glomerular filtration rate. Scand I Clin Lab Invest 1981, 41:611-6.

22. Shyh-Dye Lee, Rong-Bin Chuang, Chia-Ming Li, Wen-Han Pan: Aging of Renal Function Estimation in Elderly Community Dwellers Experiences in Taiwanese Population. Tai J Geront S Med 2006, 1:159-172.

23. Berg UB: Differences in decline in GFR with age between males and females. Reference data on clearances of inulin and PAH in potential kidney donors. Nephrol Dial Transplant 2006, 21:2577-82.

24. Iseki $K$, Nakai $S$, Shinzato $T$, et al: Increasing gender difference in the incidence of chronic dialysis therapy in Japan. Ther Apher Dial 2005, 9:407-11.

25. USRDS: USRDS 2007 Annual Data Report. National Institutes of Health, National Institute of Diabetes and Digestive and Kidney Diseases. 2007, 84.

26. Coresh J, Astor BC, Greene T, et al: Prevalence of chronic kidney disease and decreased kidney function in the adult US population: Third
National Health and Nutrition Examination Survey. Am J Kidney Dis 2003, 41:1-12.

27. Chadban SJ, Briganti EM, Kerr PG, et al: Prevalence of kidney damage in Australian adults: The AusDiab kidney study. J Am Soc Nephrol 2003, 14: S131-8.

28. Nitsch D, Felber Dietrich D, von Eckardstein A, et al: Prevalence of renal impairment and its association with cardiovascular risk factors in a general population: results of the Swiss SAPALDIA study. Nephrol Dial Transplant 2006, 21:935-44.

29. Viktorsdottir $\mathrm{O}$, Palsson $\mathrm{R}$, Andresdottir MB, et al: Prevalence of chronic kidney disease based on estimated glomerular filtration rate and proteinuria in Icelandic adults. Nephrol Dial Transplant 2005, 20:1799-807.

30. Fuiano G, Sund $S$, Mazza $G$, et al: Renal hemodynamic response to maximal vasodilating stimulus in healthy older subjects. Kidney Int 2001, 59:1052-8.

31. Miller JA, Anacta LA, Cattran DC: Impact of gender on the renal response to angiotensin II. Kidney Int 1999, 55:278-85.

32. Reckelhoff JF, Hennington BS, Moore AG, et al: Gender differences in the renal nitric oxide (NO) system: dissociation between expression of endothelial NO synthase and renal hemodynamic response to NO synthase inhibition. Am J Hypertens 1998, 11:97-104.

33. Witte EC, Lambers $H H J$, de Zeeuw $D$, et al: First morning voids are more reliable than spot urine samples to assess microalbuminuria. J Am Soc Nephrol 2009, 20:436-43.

34. Coresh J, Astor BC, Greene T, et al: Prevalence of chronic kidney disease and decreased kidney function in the adult US population: Third National Health and Nutrition Examination Survey. Am J Kidney Dis 2003, 41:1-12.

\section{Pre-publication history}

The pre-publication history for this paper can be accessed here: http://www.biomedcentral.com/1471-2369/11/20/prepub

doi:10.1186/1471-2369-11-20

Cite this article as: Xu et al:: Gender differences in age-related decline in glomerular filtration rates in healthy people and chronic kidney disease patients. BMC Nephrology 2010 11:20.

\section{Submit your next manuscript to BioMed Central and take full advantage of:}

- Convenient online submission

- Thorough peer review

- No space constraints or color figure charges

- Immediate publication on acceptance

- Inclusion in PubMed, CAS, Scopus and Google Scholar

- Research which is freely available for redistribution
Biomed Central 